\title{
Experience with transcatheter closure of secundum atrial septal defects using the Amplatzer septal occluder: a single centre study in 236 consecutive patients
}

\author{
G Fischer, J Stieh, A Uebing, U Hoffmann, G Morf, H H Kramer
}

Heart 2003;89:199-204

See end of article for authors' affiliations

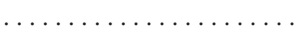

Correspondence to: Dr Gunther Fischer, Department of Paediatric Cardiology and Biomedical Engineering,

Universitätsklinikum Kiel, Schwanenweg 20 D-24105 Kiel, Germany; fischer@pedcard.uni-kiel.de

Accepted 18 September 2002

\begin{abstract}
Aim: To evaluate the safety and efficacy of transcatheter closure of secundum atrial septal defects (ASD) with the Amplatzer septal occluder.

Methods: 236 consecutive patients with a significant ASD (age 6 months to 46 years, median 5 years; body weight $6.5-79 \mathrm{~kg}$, median $18 \mathrm{~kg}$ ) were considered for transcatheter closure with the Amplatzer septal occluder; 18 patients with defects that were too large or with a deficient inferior margin were excluded from attempted transcatheter closure after initial transthoracic (4) or transoesophageal echocardiography (14).

Results: At cardiac catheterisation, devices were not implanted in 18 patients because the stretched diameter of the ASD was too large (4), the device was unstable (4), compromised the mitral valve (1), or obstructed the upper right pulmonary vein (1); eight patients with additional systemic or pulmonary vein anomalies (5) or a Qp:Qs less than 1.5 (3) were excluded after angiographic and haemodynamic assessment. Thus ASD closure was done successfully in 200 patients (procedure time 25-210 minutes, median 66 minutes; fluoroscopy time 2.5-60 minutes, median 12 minutes), among whom 22 had multiple ASDs (14) or a septal aneurysm (8). The diameter of the devices ranged between 6-34 mm. Severe procedure related complications (retroperitoneal bleeding, air embolism) occurred in two cases. At follow up ( 33 days to 4.3 years, median 2.3 years) complete closure was documented in $94 \%$, with a trivial residual shunt in 12 patients.

Conclusions: The Amplatzer septal occluder is very efficient and offered interventional ASD closure in
\end{abstract} $84.7 \%$ of our group of consecutive patients, with excellent intermediate results.
T he early limited experience of transcatheter device closure of secundum atrial septal defects (ASD) by King, Mills, and Rashkind in 1976 and $1983^{1-3}$ did not meet with general clinical acceptance. However, interventional ASD closure is now widely practised and has replaced surgical ASD closure in many centres. ${ }^{4}$ Improvements in design have made the devices retrievable, and reduction in the size of the introduction systems allows interventional treatment even in young patients. Two different types of device are in widespread use, and new devices are being introduced. ${ }^{5}$ While the patch type occlusion device-represented by the CardioSEAL, or its modification, the STARFlex occluder (NMT Medical, Boston, Massachusetts, USA) - mimics surgery by placing a patch over the ASD, the self centring Amplatzer septal occluder (AGA Medical Corporation, Golden Valley, Minnesota, USA) offers a different approach by stenting the interatrial communication. ${ }^{6}$ This unique technique makes it possible to close even large defects (up to $38 \mathrm{~mm}$ ), ${ }^{7}$ while the inability to close such large defects remains a limitation of the patch type devices. ${ }^{8}$

Since the first clinical trials with the Amplatzer septal occluder in 1995 and 1997, ${ }^{10}$ there have been many reports of excellent early follow up results after ASD closure with the Amplatzer occluder, albeit in relatively small numbers of patients. ${ }^{11-15}$ We now report our own clinical experience and midterm results with this device in 236 unselected and mostly paediatric patients who have presented with ASDs since April 1997.

\section{METHODS}

Patients and clinical details

Between April 1997 and August 2001, 236 consecutive patients with a significant ASD, demonstrated by initial trans- thoracic echocardiography (TTE), were considered for transcatheter closure with the Amplatzer septal occluder. Their ages ranged from six months to 46 years (median 4.9 years); they included 21 adults and five symptomatic children under 1 year of age. Body weight ranged from $6.5-79 \mathrm{~kg}$ (median $18 \mathrm{~kg}$ ); 16 children had a body weight of less than $10 \mathrm{~kg}$. Fourteen patients had multiple or fenestrated defects, and eight had a perforated septal aneurysm. Two patients had a significant residual ASD after previous surgery, one presented with cor triatriatum, and two further patients had large ASDs because of previous balloon atrial septostomy procedures. In addition, six patients who had previously been excluded from ASD closure with the ASDOS device (Dr Osypka GmbH, GrenzachWyhlen, Germany) were considered for closure with the Amplatzer occluder.

Routine examination before catheterisation included a standard ECG, a 24 hour Holter ECG, a chest $x$ ray, and TTE. Blood tests were done to exclude coagulation disorders-for example C- or S-protein deficiency and resistance to activated protein $\mathrm{C}$.

The manufacturer's recommended echocardiographic exclusion criterion is a distance of less than $5 \mathrm{~mm}$ from the rim of the defect to the atrioventricular valves, the coronary sinus, or the right upper lobe pulmonary vein.

After ASD closure the patients remained in the hospital for one night, and received heparin 400-500 IU/kg/d (partial thromboplastin time 50-60 seconds) for 24 hours, followed by

Abbreviations: ASD, atrial septal defect; MRI, magnetic resonance imaging; TOE, transoesophageal echocardiogram; TTE, transthoracic echocardiography 
aspirin $2-3 \mathrm{mg} / \mathrm{kg} / \mathrm{d}$ for six months. In three cases with coagulation disorders coumarins were given for six months. Before discharge an ECG and a 24 hour Holter ECG recording, a biplane chest $x$ ray, and a TTE examination were performed. Follow up examinations including ECG and TTE were scheduled at 1, 3, 12, 24, and 48 months after the procedure. The 12 month follow up examination also included a 24 hour Holter ECG recording. A short biplane cine sequence was carried out at the end of the procedure and at the 12 month follow up examination, visualising the device in a frontal and lateral view.

\section{Device installation \\ Echocardiography}

The initial TTE showed the location of the ASD, its septal rim, and its diameter and also enabled us to measure the length of the interatrial septum in the four chamber view. These measurements were used to assess the feasibility of transcatheter closure with the Amplatzer septal occluder.

\section{The device}

The Amplatzer septal occluder is a self expanding, self centring, and repositionable double disc device constructed of a mesh of 72 Nitinol wires. A 3-4 mm short cylindrical waist connects the two round discs. Basically, the Amplatzer septal occluder stretches and stents the ASD. Thus the diameter of the waist has to correspond to the so called "stretched" diameter of the ASD, determined by a balloon sizing catheter. Additionally, polyester fibres are sewn into the device promoting thrombosis and complete defect occlusion. Twenty seven different sizes with waist diameters from $4-40 \mathrm{~mm}$ are available. For devices between $4-10 \mathrm{~mm}$ the left atrial disc is $12 \mathrm{~mm}$ larger than the waist and the right atrial disc is $8 \mathrm{~mm}$ larger. For bigger devices the left atrial disc is either $14 \mathrm{~mm}$ larger than the waist (waist diameter $11-30 \mathrm{~mm}$ ) or $16 \mathrm{~mm}$ larger than the waist (waist diameter $32-40 \mathrm{~mm}$ ). The right atrial disc is $10 \mathrm{~mm}$ larger than the waist for devices of 11-40 mm. For transvenous implantation of the Amplatzer occluder, the manufacturer provides a loader, a delivery cable, and a 6-12 French long sheath. Before loading the device into the long sheath it is connected to the delivery cable by a microscrew fixed to the right atrial disc.

\section{The procedure}

In the catheterisation laboratory and before catheterisation, a biplane transoesophageal echocardiogram (TOE) was done under general anaesthesia or heavy sedation to evaluate the size and location of the defect and its margins. Vascular access was obtained from the femoral vein, and heparin ( $100 \mathrm{IU} / \mathrm{kg}$ ) and antibiotics (flucloxacillin) were given. After making a complete haemodynamic evaluation, an anomalous pulmonary vein connection was excluded by angiocardiography. The "stretched" diameter of the ASD was measured using a Meditech sizing balloon (Boston Scientific Corporation, Watertown, Massachusetts, USA). After release of a new sizing technique in 1999, a special balloon sizing catheter provided by AGA Medical Corporation or NMT Medical was used. A device with a waist diameter similar to, or in large defects up to $2 \mathrm{~mm}$ bigger than, the stretched ASD diameter was chosen.

After introducing the long sheath over the exchange guide wire into the left upper pulmonary vein, the device was inserted and deployed under fluoroscopic and TOE guidance, as described in various publications. ${ }^{9}{ }^{13} 15$ A secure and stable position of the occluder within the defect was checked by a push-pull manoeuvre (the "Minnesota wiggle"). The device and adjacent structures were then examined by TOE to ensure that there was no encroachment of the device on the atrioventricular valves or the right pulmonary veins. After releasing the device from the cable by unscrewing it, a final TOE examination was undertaken to demonstrate the position of the device and any residual shunting.

\section{RESULTS}

Between April 1997 and August 2001, successful transcatheter ASD occlusion was done in 200 of 236 consecutive patients who presented at our institution. The majority of these patients $(80 \%)$ showed a simple, single centrally located fossa ovalis ASD on echocardiographic examination, while $20 \%$ of the cases had multiple or fenestrated defects (14), an additional septal aneurysm (8), inferior extension of the defect towards the atrioventricular valves or coronary sinus (2), or an inferior-posterior extension next to the inferior caval vein ("caval defects") (24).

On TOE, the maximum defect diameter varied between 4-32 mm, while the balloon stretched diameter varied between $6.5-32 \mathrm{~mm}$. Devices with a waist diameter similar to or slightly larger than the stretched diameter were implanted, ranging between $6-34 \mathrm{~mm}$. The procedure time varied between 25-210 minutes (median 66 minutes) and the fluoroscopy time between 2.5-60 minutes (median 12 minutes), with a tendency to shorter procedural and screening times after the learning curve. Comparing the group of patients less than $10 \mathrm{~kg}$ in body weight $(\mathrm{n}=16)$ with larger patients, no statistical difference was found with respect to the procedure or the fluoroscopy time (procedure time, $\mathrm{p}=0.552$; fluoroscopy time, $\mathrm{p}=0.442$; Student's $t$ test).

Sixty three ASDs were closed with large devices of 20-34 mm; included among these were two thirds of the adult patients. Seven of 10 patients with multiple or fenestrated defects were treated with a single device, while in three patients two devices were implanted simultaneously through separate delivery systems. Defects with an additional septal aneurysm were successfully closed by catching the aneurysm during the process of configuring the right atrial disc, resulting in firm compression of the aneurysm towards the atrial septum. ASDs with an inferior-posterior location and a sufficient margin towards the inferior caval vein were closed in nine cases. On two occasions, inferiorly located ASDs with no rim towards the inferior caval vein and with an additional perforated septal aneurysm were considered unsuitable for the Amplatzer septal occluder. These were closed successfully using a patch type device (CardioSEAL). All patients who were excluded from ASD closure using the ASDOS device in previous years $(n=6)$ were treated successfully with the Amplatzer septal occluder.

Thirty six patients were excluded from transcatheter closure; among these were four of the 16 children with a body weight less than $10 \mathrm{~kg}$. Four children (body weight 7-14 kg) with large ASDs were excluded after the initial TTE examination. One of these had an inferior-posterior ASD with no rim towards the inferior caval vein, which was clearly defined by TTE.

At the time of cardiac catheterisation, 14 further patients were excluded after TOE examination, as follows. Eight had inferior-posterior defects and no rim near to the orifice of the inferior caval vein. Two had defects that were very near to the coronary sinus. Another had a large defect that was near the entrance of the superior caval vein, with only a small rim towards the right pulmonary veins. One symptomatic adult and two children (body weight $10-14 \mathrm{~kg}$ ) had a defect diameter of more than $26 \mathrm{~mm}$ on TOE. The adult was excluded at a time when no devices were available with a waist diameter greater than $26 \mathrm{~mm}$.

Eighteen further patients were excluded after initial angiography, haemodynamic evaluation, balloon sizing of the defect, or trial of device placement. Two of these showed drainage of the right pulmonary veins to the superior caval vein and three had azygos continuation of the inferior caval vein. Three patients with a small ASD were excluded after demonstration of a left to right shunt with a pulmonary to systemic blood flow index (Qp:Qs) of less than 1.5.

After balloon sizing four further patients were excluded. Three of these had large inferior-posterior defects with a 

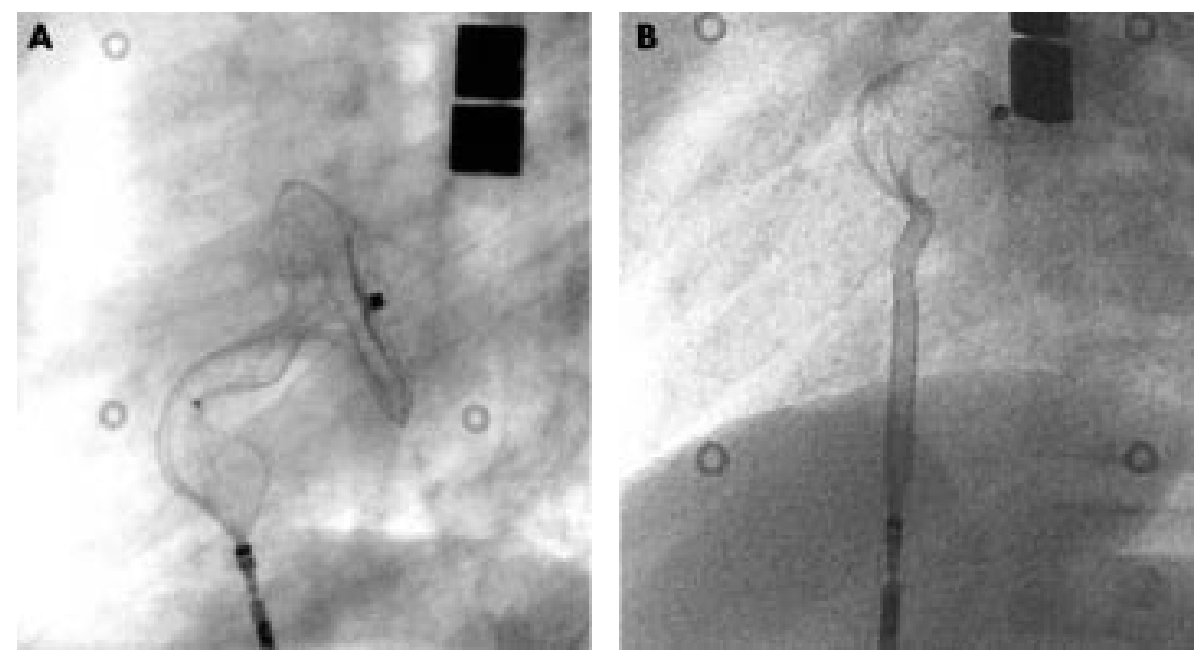

Figure 1 Cobra head malformation of (A) the right atrial and (B) the left atrial retention disc.

stretched diameter of between $22 \mathrm{~mm}$ and more than $30 \mathrm{~mm}$ and an insufficient margin towards the inferior caval vein. One patient who showed two waists during balloon sizing had a duplication of the septum primum, which was confirmed at surgery.

Despite repeated trials, device placement failed in three cases because of insufficient inferior margins (1) or large defects with a floppy septum (2), as shown by dislocation of the device into the right atrium on gentle traction of the delivery cable. A trial of device placement in a patient with azygos continuation failed owing to the unusual azygos route and our inability to deploy the device correctly. This experience led us to exclude two other patients with azygos continuation from transcatheter closure. Mitral regurgitation following device placement occurred in one case (a small child of $16 \mathrm{~kg}$ body weight) who had an inferior-anterior rim of $5 \mathrm{~mm}$ and needed a $26 \mathrm{~mm}$ device. After retrieving the occluder, which was still connected to the delivery cable, the mitral valve immediately became competent. On another occasion (in a child of $13 \mathrm{~kg}$ body weight), TOE showed obstruction of the orifice of the right pulmonary vein after implantation of a $16 \mathrm{~mm}$ device. In this case, the device was easily recaptured using a 12 French long sheath and a "goose neck" snare.

A so called "cobra head" configuration (fig l) - - malformation of the Amplatzer occluder during deployment-occurred in seven cases and led to a prolonged procedure and prolonged fluoroscopy time. In six cases retrieval of the device into the long sheath and redeployment or exchange was achieved successfully. In the seventh case (the azygos continuation), the cobra head malformation of the left atrial disc could not be corrected and the procedure had to be abandoned.
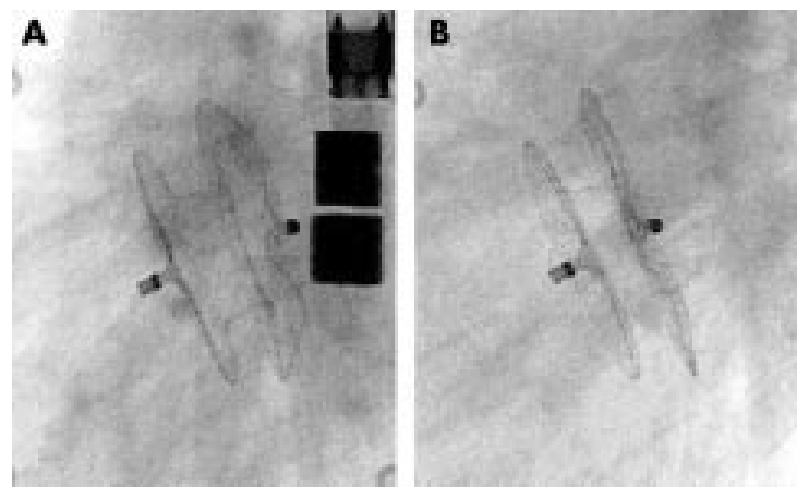

Figure 2 Lateral view of an implanted Amplatzer septal occluder $(17 \mathrm{~mm})$ directly after implantation $(A)$ and at the one year follow up examination (B).
At the end of the procedure, the diameter of the connecting waist of the implanted occluder was measured fluoroscopically and was found to be significantly smaller than the original size, at (mean (SD)) 4.1 (1.2) $\mathrm{mm}$. The distance between the central posts of the right and left retention discs was also measured from inside to inside. These results were compared with measurements on a short cine sequence at the 12 month follow up examination $(\mathrm{n}=36)$ and showed a tendency to a flatter appearance of the occluder with the passage of time (fig $2)$ : distance between central posts after implantation, 12.6 (2.4) $\mathrm{mm}$; at 12 month follow up examination, 9.9 (2.1) $\mathrm{mm}$. Two patients (weighing 6.5 and $16 \mathrm{~kg}$ ) in whom large devices were installed were also examined by magnetic resonance imaging (MRI) at follow up examination (fig 3).

On colour flow Doppler, residual shunting-including foaming through the wire mesh of the device-was seen in $83 \%$ of cases directly after implantation. By the time of discharge, 24 hours after ASD closure, the rate of residual leakage had decreased to $17 \%$. During further follow up examinations ( 33 days to 4.3 years, median 2.3 years) the complete closure rate has reached $94 \%$. A trivial residual shunt is still present in 12 patients. While one of these patients received coumarin for six months owing to a coagulation disorder, the majority had an additional ASD $(n=9)$ that was not "stented" but only covered by the retention disc of the device, or had defects with an additional septal aneurysm $(\mathrm{n}=2)$.

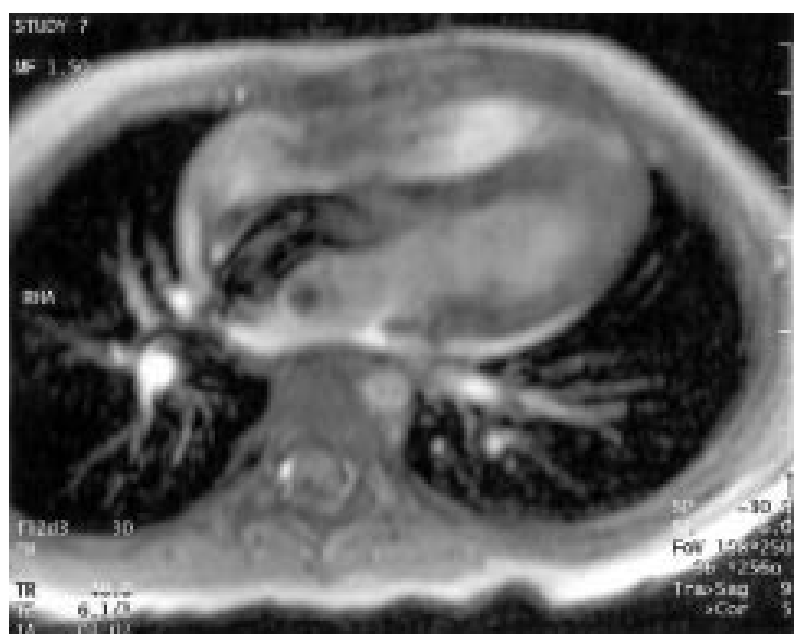

Figure 3 Uncompromised diastolic filling of the ventricles demonstrated by cine magnetic resonance imaging. Note the "banana shaped" configuration of the Amplatzer septal occluder (24 mm). 

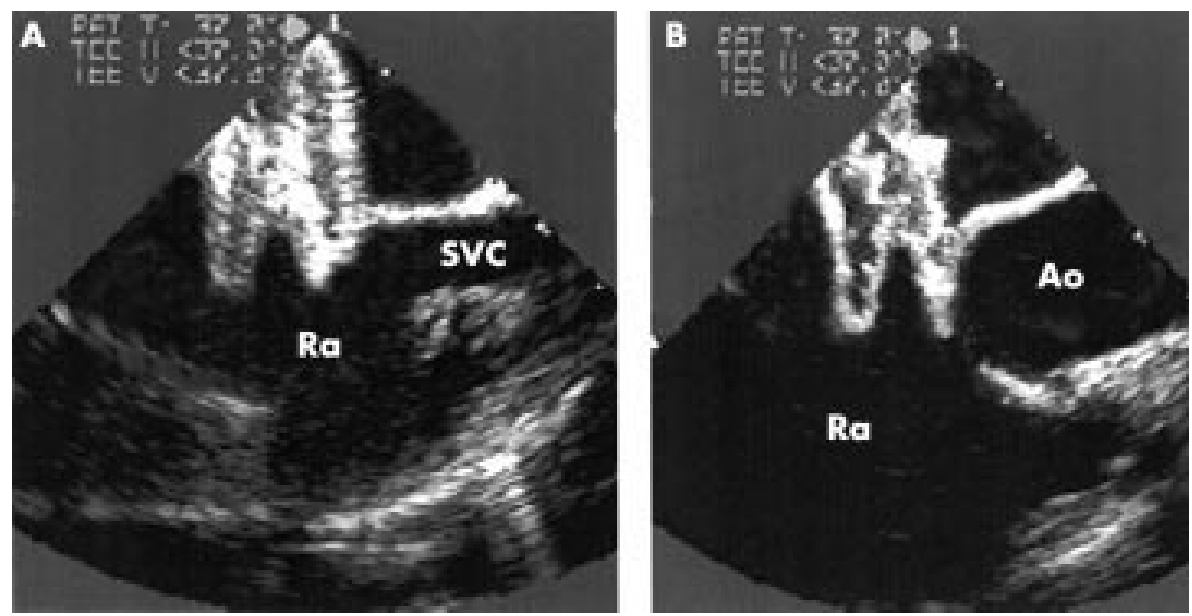

Figure 4 Transoesophageal echocardiography showing misplacement of a $26 \mathrm{~mm}$ Amplatzer septal occluder while it was still connected to the delivery cable; the left atrial disc slipped through the defect into the right atrium $(\mathrm{Ra})$ at its cranial portion next to the superior caval vein (SVC) (A) and the aortic root $(\mathrm{Ao})(\mathrm{B})$
There were two major procedure related complications at our institution. The first was a retroperitoneal haematoma that required surgery early after successful ASD closure. In this case, a 7 year old girl, rupture of a small branch of the femoral artery during puncture of the femoral vein led to severe bleeding during the first hours after ASD closure while the patient was on heparin. The second complication occurred in an 11 year old girl who was under heavy sedation and was not intubated: air embolism to the right heart occurred while the Amplatzer occluder was already in place but was still connected to the delivery cable. There were no sequelae of this event.

ECG abnormalities associated with transcatheter closure occurred in two cases. A 32 year old man developed recurrent atrial flutter three months after uncomplicated ASD closure with a $30 \mathrm{~mm}$ occluder. In this patient long term maintenance of sinus rhythm was achieved with sotalol. In another case (a child of $11 \mathrm{~kg}$ ), atrial flutter which occurred directly after ASD closure with a $19 \mathrm{~mm}$ occluder was resolved by giving propafenone for 48 hours. No other early or late complications-such as pericardial effusion, compromise of intracardiac structures, device embolisation, cerebral embolism, or endocarditisoccurred during follow up.

At the 12 month follow up the integrity of the occluder was demonstrated by fluoroscopy in all cases. No device damage, such as broken Nitinol wires or detachment of the central posts, was seen.

\section{DISCUSSION}

The ease of implantation and the superior success rate of ASD closure with the Amplatzer septal occluder ${ }^{4}{ }^{16-21}$ has led to the widespread employment of transcatheter occlusion of ASD and has replaced routine surgical closure in many centres. There is no doubt that this success rate is a result of the design of the Amplatzer occluder, which is completely different from the patch type systems. The most important aspect is that the device's waist between the left and right retention discs is a stent, resulting in self centring within the defect. Thus the Amplatzer occluder requires only a small rim around the defect for firm cross clamping by the retention discs. The unique design, using a Nitinol mesh, overcomes many of the limitations of other ASD occlusion devices. Large delivery systems are not necessary, the Amplatzer septal occluder is retrievable without damaging the device, the device is self centring, and occluders large enough to close defects of up to $40 \mathrm{~mm}$ in diameter are available. Other devices can only close defects of up to $24 \mathrm{~mm}$ diameter, ${ }^{82}$ which excludes many patients with larger defects. In our cohort, 21 ASDs were larger than $24 \mathrm{~mm}$.

TTE and TOE have proved to be very important tools for the exact anatomical delineation of the defect within the atrial septum. As it is difficult to examine defects in older patients using TTE, inspection of the exact nature of the septal rim near to other cardiac structures like the atrioventricular valves, the right pulmonary veins, or the inferior caval vein must be carried out with TOE before catheterisation. Defects near the entrance of the inferior caval vein, which should easily be identified by TTE in the paediatric age group, occurred in $10 \%$ of our cohort $(\mathrm{n}=24)$ and proved to be suitable for transcatheter closure only if a sufficient septal rim was present towards the orifice of the vein; this was the case in less than $50 \%$ of the patients ( 11 of 24 ). In two of these cases with no inferior septal rim, an additional septal aneurysm was present and patch type devices were implanted successfully under TOE guidance.

The manufacturer's recommended exclusion criterion is an ASD with a rim to the atrioventricular valves of less than $5 \mathrm{~mm}$. Device closure of these inferior and anterior defects could compromise the mitral valve. This was seen in one of our patients with a rim of only $6 \mathrm{~mm}$. In that patient a $26 \mathrm{~mm}$ device did cause mitral regurgitation. Similarly, the device can obstruct the orifice of the right pulmonary veins in rare cases with a more superior and posterior defect location; this happened in one of our patients who received a $16 \mathrm{~mm}$ occluder. In both cases the device was retrieved without problems.

The possibility of the retention discs impinging on sensitive structures is particularly pertinent when dealing with small children. An additional consideration is the length of the interatrial septum, which should be sufficient to accommodate the device. However, the fact that we had to exclude only four of our 16 children who weighed less than $10 \mathrm{~kg}$ shows that device closure can be accomplished even in small children. In fact there was no difference in procedure or screening times between this group and the larger patients.

TOE is also very important to ensure the correct positioning of the device before and after its release. This is critical in the closure of large defects because the left atrial retention disc in bigger devices is relatively small in relation to the waist diameter. Because of this, its cranial portion tends to slip through the defect (fig 4), and this may result in early or even late embolisation of the device. Furthermore, TOE is useful in directing the catheter through the largest communication in cases of multiple ASDs, and it helps to reduce the screening time significantly. It has even been suggested that ASD closure with the Amplatzer occluder can be carried out under TOE guidance alone. ${ }^{23}$

Cobra head malformation of the Amplatzer septal occluder is sometimes difficult to overcome and may prolong the procedure. While it occurred more often in the past with the first generation of Amplatzer devices, it still may happen, particularly if there is not enough space for the configuration of 


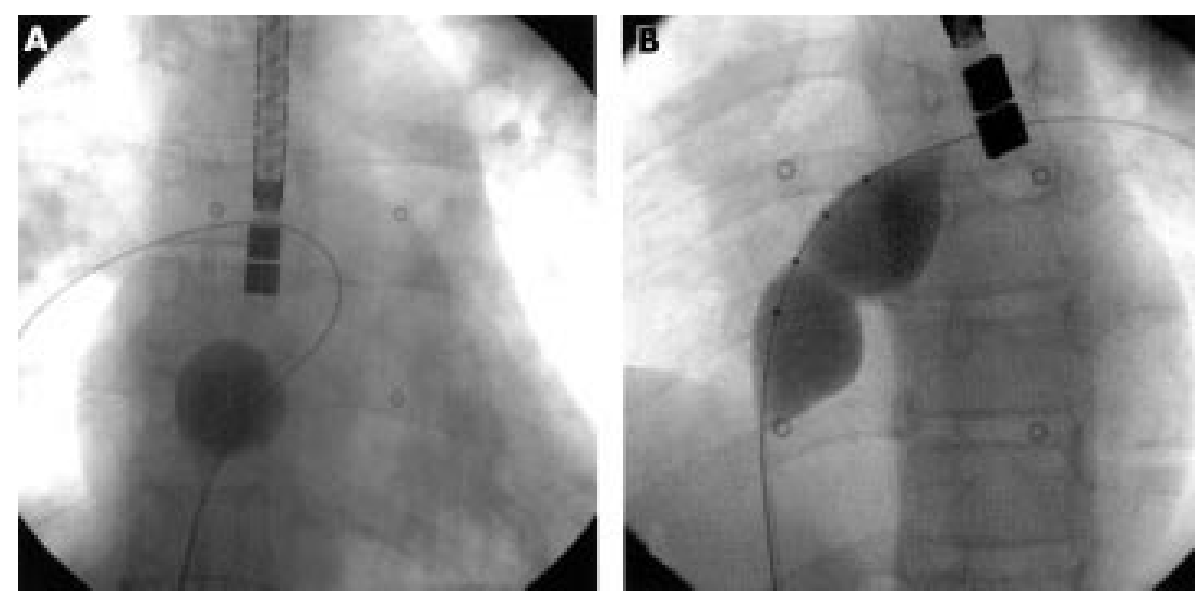

Figure 5 Sizing procedure using the Meditech sizing balloon (A) and the new NMT sizing balloon (B). The waist of the balloon (B) clearly indicates the "stretched" diameter of the atrial septal defect.

the left or right atrial disc within the left or right atrium in a small patient. This can cause twisting of the occluder during deployment owing to the leading edge of the device catching on the atrial free wall or the appendage. ${ }^{24} 25$ This problem can be managed by retrieval and redeployment of the occluder or even by exchanging the device. In the case of a patient with azygos continuation, ASD closure was not possible because the cobra head malformation of the left atrial disc could not be overcome. This was the result of the unusual catheter route through the azygos vein, which made any variation of deployment within the left atrium impossible. We rejected alternative approaches, such as the hepatic or jugular routes, and this experience led us to exclude two further patients presenting with azygos continuation from transcatheter closure.

A point of criticism of the Amplatzer septal occluder is that it sometimes appears bulky after implantation. This may be the case if, owing to inaccurate balloon sizing, a device with too large a stent is implanted. "Mushrooming" of the retention discs can then occur. This is more likely when the stent is compressed so that the waist measured on fluoroscopy is more than $4 \mathrm{~mm}$ smaller than the nominal diameter of the stent. Inaccurate balloon sizing is now rare owing to the introduction of new static sizing balloons (AGA Medical and NMT) (fig 5); overestimation of the defects has become rare, and so has mushrooming.

Our cine measurements of the implanted device showed a mean (SD) thickness of $12.6(2.4) \mathrm{mm}$, with a tendency to a flatter appearance at follow up $(9.9(2.1) \mathrm{mm})$. Inaccurate sizing of the ASD is not the only cause of malformation of the implanted occluder; it could also happen if the diameter of the retention discs exceeds the length of the interatrial septum. This occurred in one patient. In that case the device with its flexible retention discs propped against the atrial free walls, which led to a deflection and the impression of a banana shaped deformation. To avoid such a deformation and any potential obstruction of cardiac structures, this experience led to us making an initial assessment of the interatrial septal length from the four chamber view on TTE as an important body weight dependent variable. In cases of large ASDs the septal length should not be exceeded by the diameter of the occluder. The length of the interatrial septum in the patient with the banana shaped device (body weight $16 \mathrm{~kg}$ ) was $35 \mathrm{~mm}$, while the retention discs had a diameter of $36 \mathrm{~mm}$ (right disc) and $38 \mathrm{~mm}$ (left disc). In addition to echocardiographic follow up studies, this patient also had an MRI study, which showed no evidence of any device related obstruction. Owing to the fact that the wire mesh of the Amplatzer occluder is non-ferromagnetic, magnetic resonance imaging —which was also done in another patient—was able to show the implanted device itself as well as its neighbouring cardiac structures (fig 3). From this limited experience, we conclude that MRI, in addition to echocardiography, will allow non-invasive follow up examination and probably has the potential to replace $x$ ray for ASD closure in the future.

An interesting observation is that heart cycle dependent movement of the elastic Nitinol wire mesh directly after implantation of the occluder could no longer be seen in any of the implanted devices on the cine sequence taken one year after implantation. This observation may be an indicator of endothelialisation of the device and it could be interpreted as a potential advantage that protects the integrity of the occluder. At the one year follow up fluoroscopy showed no fractures of the Nitinol wires. This is in contrast with the $6-14 \%$ incidence of arm fractures with the CardioSEAL or STARFlex devices. ${ }^{826}$

The high percentage of previously reported residual leaks, which were up to $53 \%$ with the first generation of patch type devices, ${ }^{27-29}$ has improved over the years but is still $20 \%$ at one year after the procedure, as reported recently in the multicentre experience using CardioSEAL and STARFlex devices. ${ }^{8}$ With the Amplatzer occluder we observed a complete occlusion rate of $95.5 \%$ during follow up, with only eight patients still showing a trivial shunt on colour flow Doppler. Though these residual leaks are trivial, it seems of interest that with one exception they occurred only in patients who had an additional ASD or defects with an additional septal aneurysm. The exception was a patient who received coumarin for six months after closure of a single fossa ovalis type of ASD, and one could speculate whether the coumarin treatment promotes residual leakage. In the other cases it seems clear that additional tissue captured by the retention disc, or additional defects which were not stented but only covered by the discs, prevents complete defect occlusion and promotes residual leakage.

Whether or not one should use general anaesthesia for specific interventional procedures may be a question of economics for some institutions or simply a question of the availability of anaesthetic cover. On the other hand, unlike adult patients, a child will not tolerate the TOE probe without heavy sedation. Heavy sedation (for example, with propofol or ketamine) and continued spontaneous breathing may carry a risk of air embolism through the long sheath, owing to the negative intrathoracic pressure. This occurred in one of our patients under propofol sedation. When this happened, the device was already in place and closed the communication to the left heart. While this event was without sequel, it was striking enough to result in a change of policy in our institution. In order to avoid irreversible myocardial or cerebral damage, or even death after air embolism to the left heart, we now perform all interventional ASD closures under general anaesthesia with mechanical ventilation.

Up to now, we have seen only two patients who developed arrhythmias after ASD closure with the Amplatzer occluder. In the case of a 32 year old man with atrial flutter, development 
of the arrhythmia seemed to be the result of long standing right atrial volume overload and dilatation rather than being device related, while in the case of a young child the onset of atrial flutter was clearly procedure related. Our experience of the sudden onset of complete atrioventricular block that occurred 4.5 years after implantation of an ASDOS device makes us believe that all patients need 24 hour Holter ECG recording at regular intervals.

\section{Conclusions}

To date, our single centre experience with the Amplatzer septal occluder shows excellent closure results for the great majority of consecutive patients presented with an ASD. However, we believe that, despite our encouraging intermediate results, lifelong observation of this group of patients is required.

\section{Addendum}

After this paper was accepted, a significant event occurred during follow up. Four to five years after a successful and uneventful ASD closure with a $20 \mathrm{~mm}$ Amplatzer occluder, a 13 year old girl suddenly developed a left, predominantly brachiofacial, hemiparesis. Computed tomography showed a recent infarction in the area supplied by the right medial cerebral artery. On TOE no unusual finding, thrombus formation or residual shunt were seen. In the ensuing two weeks after the cerebral stroke the patient's symptoms completely resolved. So far, this is the only case of a delayed episode of embolisation in at least 25000 Amplatzer implants (Dr Kurt Amplatz, personal communication, 2002). Although there is no proof, we consider that, in a 13 year old patient with an implanted device and a cerebral infarct, the most likely source of embolisation is the device. In summary, this event confirms our recommendation of life long observation after device implantation.

\section{ACKNOWLEDGEMENT}

We gratefully acknowledge Professor Michael Tynan, London, for his critical revision of the manuscript.

\section{Authors' affiliations}

G Fischer, J Stieh, A Uebing, U Hoffmann, G Morf, H H Kramer, Department of Paediatric Cardiology and Biomedical Engineering, Universitätsklinikum Kiel, Kiel, Germany

\section{REFERENCES}

1 King T, Mills M. Secundum atrial septal defects: nonoperative closure during cardiac catheterization. JAMA 1976;235:2506-9.

2 Mills NL, King TD. Non-operative closure of left-to-right shunts. J Thorac Cardiovasc Surg 1976;72:371-8.

3 Rashkind W. Transcatheter treatment of congenital heart disease. Circulation 1983:67:711-16.

4 Berger F, Ewert P, Bjornstad PG, et al. Transcatheter closure as standard treatment for most interatrial defects: experience in 200 patients treated with the Amplatzer septal occluder. Cardiol Young 1999;9:468-73.

5 Latson LA, Zahn EM, Wilson N. Helex septal occluder for closure of atrial septal defects. Curr Intervent Cardiol Rep 2000;2:268-73.

6 Sharafuddin MJA, Gu X, Titus J, et al. Transvenous closure of secundum atrial septal defects: preliminary results with a new self-expanding nitinol prosthesis in a swine model. Circulation 1997;95:2162-8.
7 Berger F, Ewert P, Dahnert I, et al. [Interventional occlusion of atrial septum defects larger than $20 \mathrm{~mm}$ in diameter]. Z Kardiol 2000;89: 111 19-25

8 Carminati M, Giusti S, Hausdorf G, et al. A European multicentric experience using the CardioSEAL and STARFlex double umbrella devices to close interatrial communications holes within the oval fossa. Cardiol Young 2000;10:519-26.

9 Masura J, Gavora P, Formanek A, et al. Transcatheter closure of secundum atrial septal defects using the new self-centering Amplatzer septal occluder: initial human experience. Cathet Cardiovasc Diagn 1997;42:388-93.

10 Biornstad PG, Thaulow E, Smevik B, et al. [Catheter treatment of congenital heart defects. Arterial septal defects and open ductus arteriosus]. Tidsskr Nor Laegeforen 1997;117:2961-4.

11 Thanopoulos BD, Laskari CV, Tsaousis GS, et al. Closure of atrial septal defects with the Amplatzer occlusion device: preliminary results. J Am Coll Cardiol 1998;31:1110-16.

12 Chan KY, Yip WC, Godman M. Transcatheter occlusion of atrial septal defects: an initial experience with the Amplatzer septal occluder. $J$ Paediatr Child Health 1998;34:369-73.

13 Berger F, Ewert $P$, Stiller $B$, et al. [Initial clinical results with the Amplatzer septal occluder - a self-centering double disc for occlusion of atrial septal defects]. Z Kardiol 1998;87:185-90.

14 Wilkinson JL, Goh TH. Early clinical experience with use of the "Amplatzer septal occluder" device for atrial septal defect. Cardiol Young 1998;8:295-302.

15 Fischer G, Kramer HH, Stieh J, et al. Transcatheter closure of secundum atrial septal defects with the new self-centering Amplatzer septal occluder. Eur Heart J 1999:20:541-9.

16 Chan KC, Godman N, Walsh K, et al. Transcatheter closure of atrial septal defect and interatrial communications with a new self expanding nitinol double disc device (Amplatzer septal occluder): multicentre UK experience. Heart 1999:82:300-6.

17 Moore JW, Norwood JB, Kashow KM, et al. Closure of atrial septal defects in the cardiac catheterization laboratory: early results using the Amplatzer septal occlusion device. Del Med J 1998;70:513-16.

18 Pfammatter JP, Friedli B, Oberhansli I, et al. [Nonsurgical occlusion of an atrial septal defect in childhood: initial Swiss experiences]. Schweiz Rundsch Med Prax 2000;89:225-31

19 Radhakrishnan S, Marwah A, Shrivastava S. Non surgical closure of atrial septal defect using the Amplatzer septal occluder in children feasibility and early results. Indian Pediatr 2000;37:1 181-7.

20 Waight DJ, Koenig PR, Cao QL, et al. Transcatheter closure of secundum atrial septal defects using the Amplatzer septal occluder: clinical experience and technical considerations. Curr Intervent Cardiol Rep 2000;2:70-7.

21 Walsh KP, Maadi IM. The Amplatzer septal occluder. Cardiol Young 2000;10:493-501

22 Hausdorf G, Kaulitz R, Paul T, et al. Transcatheter closure of atrial septa defect with a new flexible, self-centering device (the STARFlex Occluder). Am J Cardiol 1999;84: $1113-16$, A 10.

23 Ewert P, Daehnert I, Berger F, et al. Transcatheter closure of atrial septal defects under echocardiographic guidance without $X$-ray: initial experiences. Cardiol Young 1999;9:136-40.

24 Cooke JC, Gelman JS, Harper RW. Cobrahead malformation of the Amplatzer septal occluder device: an avoidable complication of percutaneous ASD closure. Cathet Cardiovasc Intervent 2000;52:83-5; discussion 86-7.

25 Mazic U, Gavora P, Masura J. "Cobra-like" deformation of an Amplatzer septal occluder. Pediatr Cardiol 2001;22:253-4.

26 Pedra CA, Pihkala J, Lee KJ, et al. Transcatheter closure of atrial septal defects using the Cardio-Seal implant. Heart 2000;84:320-6.

27 Carminati $M$, Hausdorf $G$, Tynan $M$, et al. Initial clinical experience of transcatheter closure of secundum atrial septal defect with a septal occlusion system. A multicenter European study. Eur Heart J 1997;18(suppl): 136.

28 Boutin C, Musewe NN, Smallhorn JF, et al. Echocardiographic follow-up of atrial septal defect after catheter closure by double-umbrella device. Circulation 1993;88:621-7.

29 Justo RN, Nykanen DG, Boutin C, et al. Clinical impact of transcatheter closure of secundum atrial septal defects with the double umbrella device. Am J Cardiol 1996;77:889-92. 